\title{
Noble Metals Potential of Gudjareti-Khachkovi Ore Field, Georgia
}

\author{
Davit Bluashvili ${ }^{1}$, Giorgi Mindiashvili ${ }^{2, *}$ \\ ${ }^{1}$ Department of applied Geology, Georgian Technical University, Tbilisi, Georgia. \\ ${ }^{2}$ Department of Geology, Faculty of Exact and Natural Sciences, Ivane Javakhishvili Tbilisi State University, Tbilisi, Georgia.
}

\begin{abstract}
How to cite this paper: Davit Bluashvili, Giorgi Mindiashvili. (2021) Noble Metals Potential of Gudjareti-Khachkovi Ore Field, Georgia. Engineering Advances, 1(2), 47-49.

DOI: 10.26855/ea.2021.12.003
\end{abstract}

Received: November 24, 2021

Accepted: December 17, 2021

Published: December 27, 2021

*Corresponding author: Giorgi Mindiashvili., Department of Geology, Faculty of Exact and Natural Sciences, Ivane Javakhishvili Tbilisi State University, Tbilisi, Georgia.

Email: giorgim1994@gmail.com

\begin{abstract}
Geological characteristics of Adjara-Trialeti Gujareti-Khachkovi ore field are reviewed in the annotation work. The ore field is tectonically highly complicated, various type dysunctives and fractures are observed. According to opening quality the following take place at the investigation territory: invisible, closed and open type fractures. Exactly the mentioned type fractures represent environment convenient for oreing-down. According to oreing-down intensity, two units are selected now within the ore field areas: Gujareti-to West and Khachkovi (Tskarostavi) - to East, which are spatially isolated from each other by less mineralized uplift block of Tarsoni. Considering geological structure of the region, in particular, magmatism and disjunctive structure characters, convenient conditions are made for magmatic systems within ore field areas. In particular, in adjacent line of Arjevani-Bakuriani fault, all conditions for establishing hydrothermal zones are made. Orthogenetic origin hydrotherms as well as meteoric waters may take part in ore production; they make metal extraction from containing rocks. In our opinion, active contamination of fluids and meteoric waters might take place, resulted of which Gujareti-Khachkovi ore field was formed.
\end{abstract}

\section{Keywords}

Ore field, oreing-down, ore observation, fold system, fault, calve and thrust fractures, hydrotherms, contamination

\section{Introduction}

One of the geological tasks of the Adjara-Trialeti geological mapping partly during 1978-82 was conducting of mass-prospecting of metals deposits [1-3]. Prospecting was carried out simultaneously with additional geological study of the area using methods of foot-path radiometric survey (1:50000), radiometric profiling along the mining workings, radiometric sampling and pearl flourimetric analysis of geochemical and trench samples aiming defining of the infiltrative and hydrothermal type metals deposits formation possibilities. The survey involved $1,536 \mathrm{~km}^{2}$ area. During the entire time of working activities, measurements of rocks gamma-activities were taken using radiometric device. СРП68-01. Special attention was paid to altered zones, fractures, disjunctive dislocations, distribution areas of intrusive and effusive bodies. During the metal prospecting process was conducted radiohydrogeological sampling of springs and water spots for I, II and III elements, Methodology of radiometric observations, checking of devices sensitivity, documentation record corresponded to existed demands. During geological-mapping and prospecting field trips sampling of rocks fur lithogeochemical study by spectral analysis was carried out. During last decades significant perspectives on the gold and silver mineralization discoveries within the Achara-Trialeti folded system have been detected as a result of conducted work. Within the folded [4] zone occur gold-silver ore fields mainly represented by sulfide mineralization whose commercial importance and scales have not been defined yet. From this point of view are interesting Dzama, Gudjareti-khachkof Zekari, Guria and Achara ore fields. On the basis of previously conducted geological works in the 
alluvial sediments of the rivers Dzama, Gudjareti, Kaburi, Khachkof and etc. was detected presence of placer gold represented by free gold fine grains. Before conducting of estimation work in Khackovi gold-ore occurrence, general-exploration work in 1:25000 scale were conducted within Gudjareti-khachkof ore field in 1980-1985. As a result within the mentioned ore field were studied several gold-polimetallic ore occurrences among which the most prospective is the Gudjareti gold-polimetallic ore occurrence. Positive results obtained as a result of general-prospecting work became a basis for the conducted exploration-estimating work project.

Field geological work has been conducted within $5 \mathrm{~km}^{2}$ area (scale 1:2000) by over-ground and underground mining workings, whose documentation was carried out by radiometric measurements.

\section{Physical-Geographic description of Region}

Gudjareti-Khachkovi ore field is located in the central and south part of the Achara-Trialeti folded system with related complex transport conditions. It could be reached from Tbilisi by two ways: the first-passing through the regional center Tsalka (distance $200 \mathrm{~km}$ ), where about quarter of the road could be used for vehicles only in dry weather; the second (longer and in all kinds of weather)-Gori, Borjomi, Gudjareti $(280 \mathrm{~km})$. The camp is located in the village Khachkovi. The topography within the occurrence and around it is mountainous, with sharply dissected rocky failures (rock-falls) and peaks. The highest peak on the territory of the ore occurrence is 2,140 meters high.

The drainage system is represented by the rivers Rekha, Gudjareti and their numerous tributaries of various profiles with characteristic for ordinary mountain-rivers riverbeds and waterfalls. The major part of the territory represents the alpine zone used for pastures. Lower parts of the canyons is mainly covered by lead and mixed forests.

\section{Results}

\subsection{Noble metals distribution in major ore minerals}

In order to specify geochemical features of some ore minerals and obtained from samples pan-concentrates using binocular were extracted mono-mineral fractions of pyrite, chalcopyrite, sphalerite, galena, covellite, malachite, azurite and iron hydroxide. They were analyzed by semiquantative methods on 20 elements; by atomic-absorption spectral-photometric method on gold and silver; by polarographic method on selenium, tellurium, cadmium (the latter only in sphalerite).

According to obtained by spectral method results increased grades of copper are detected nearly in all ore minerals including gold and is characteristic feature of the Achara-trialeti folded system from the point of view of metallogenic specialization. Increased values of lead are detected in sphalerite apparently caused by presence of fine inclusions of galena in sphalerite. Zinc is nearly evenly distributed in all ore minerals. The exception is pyrite whose principle part was formed earlier than sphalerite during ore-formation processes.

Maximum value of cadmium is common for sphalerite. Increased content of cadmium is detected in galena and chalcopyrite. It should be mentioned, that cadmium content is not detected in copper minerals of oxidized zone. Stibium and bismuth content is detected in galena and should be caused by finely-dispersive inclusions of stibium and bismuth sulfosalts in galena. Presence of Sb in sphalerite could be explained by presence of galena inclusions in sphalerite. Tin in all assayed minerals is evenly distributed in low amounts, not characteristic for mentioned minerals in general. The exceptions are pyrite and covellite where tin content is relatively increased. Very often covellite is replaced in pyrite.

Low content of evenly distributed barite is detected in hypergene minerals. Iron hydroxide is characterized by relatively high content of this mineral. High values of manganese and molybdenum content is detected in iron hydrogene minerals.

Increased values of $\mathrm{Co}$ and $\mathrm{Ni}$ grades are detected in pyrite and iron hydroxide and chalcopyrite. It could be supposed, that $\mathrm{Co}$ and $\mathrm{Ni}$ are isomorphic admixtures of pyrite and in less amount is chalcopyrite.

Noble metals detected on ore minerals samples with small weight (about $40 \mathrm{mg}$ ) showed, that gold is present mainly in chalcopyrite as mechanic admixture proved by mineralogical study of mineralized samples polished thin sections, where are well-observed relatively course gold grains inclusions in chalcopyrite

In the pyrite and iron hydroxide distribution of gold is of dual character. At minor $0.2 \mathrm{~g} / \mathrm{t}$ and lower grades, characteristic for the pyrites from hydrothermally altered zones, apparently gold and pyrite formation coincides in time. As for directly linked to ore bodies pyrite, it comprises $1 \mathrm{~g} / \mathrm{t}$ and more grades of gold and is related to later overprinted quartz-chalcopyrite, quartz-galena-sphalerite stages.

Relatively high grades of silver are characteristic for galena and chalcopyrite. It could be explained by simultaneous input (delivery) of silver, lead and copper by ore-forming fluids. Increased content of silver is defined also in iron-hydroxide caused by redistribution of existed forms of silver during hyper-genesis and good absorption of iron hydroxide.

Pyrite is characterized by low silver content, less than gold. Apparently, the major part of silver takes part in pyrite 
together with native gold as its compound (maybe as electrum). Gold and silver interrelation varies in pyrite takes part not only as included in gold element, but as its own minerals, grey ore; silver sulfosalts and other undetected for us types.

\section{Conclusion}

The ore phenomena we have studied are typical post-magmatic hydrothermal formations. The favorable geodynamic regime of the region, the relevant tectonic structure of the region, the presence of physico-chemical barriers, the presence of fluorine fluids and the conducting fluids participate in the formation of this type of ore formation [5-6]. All of the above factors are involved in the formation of the mineral phenomena we have studied, namely, they are formed in the region of the collision geodynamic regime, due to which magmatic foci are activated. In areas of strong regional folds and fractures, rocks undergo intense cracking, crushing, and cracking, creating favorable structural and physico-chemical barriers to the deposition of ore elements. In addition, regional structures, in our case, Arjevan-Bakuriani regional cracking can be considered as ore distribution system, and steep slopes and small-amplitude sediment-type fractures can be considered as ore mining. As for the hearth of the transmitting fluids, the issue here is much more complicated. In our opinion, both magmatic juvenile fluid system and meteorite waters are involved in the formation of ore manifestations. Contamination of these two solutions to some extent led to the formation of a discharge-circulating hydrotherm, a change in the phases of the thermodynamic regime leading to the release of dissolved useful components into the solution. We do not rule out the participation of younger, low-temperature extruder solutions, as evidenced by the presence of renal textures, the formation of the latter is associated with the coagulation of colloidal solutions. It is believed that initially the movement of fluids was carried out by diffusion, while the condensation of fluids as hydrothermal solutions reduced the degree of diffusion and replaced the transfer of the substance with further infiltration. It can be argued that Khachkov ores are genetically related to the postmagmatic-hydrothermal phase of orthomagic small subintrusive stem bodies of the Kviran diorite intrusive. These diorite stocks should be a source of useful components. The Khachkov deposit is a peripheral part of the Gujarat-Khachkov ore field, within which the developed propylite and gold-bearing quartz-polymetallic mineral and impregnated mineralization are predominantly related to the action of the convection system. It is probable that at a later stage metamorphic regeneration of ores must have taken place along the fault zones and their fault cracks. It is possible that the hydrothermal solution was reactivated on the already existing ore bodies and to some extent they were assimilated and then treated in physico-chemical conditions favorable for the extraction.

\section{Acknowledgements}

This research [PHDF-21-179] has been supported by Shota Rustaveli National Science Foundation of Georgia (SRNSFG).

\section{References}

[1] Адамиая Ш., А., et al. (1974). Adshara-Trialetic problem and problem of education blogging intrusion of the Black Sea. Ж. Geotectonics. 1974, N.1

[2] Gamkrelidze, I. P. (1976). Mechanism of formation of tectonic structure and some problems of tectogenesis. Ed. I need it. Tbilisi, 1976.

[3] Beradze, R. Sh., Gamrekeli, G. B., et al. (1982). Geological study of squares in scale 1: 50000 in the area of leaves K-38-76-A, B, B, G for 1978-82. Report Trialetskoy GSP, geol. Funds, Tbilisi, 1982.

[4] Буадзе, В. И. (1991). Problems of forecasting evil weapons. Tilisi 1991.

[5] Bluashvili, D., Mindiashvili, G. (2020). Mining Journal. Structural-Geological position of Gudjareti-Khachkovi ore field. Tbilisi, Georgia. 2020.

[6] Bluashvili, D., Benashvili, K., Mindiashvili, G., Makadze, D. (2020). Bulletion of the Georgian National academy of sciences. Vol. 14, no. 3, 2020. New data on the Dzama-Gujareti ore Knot (Georgia). Tbilisi. 